\title{
perifèria
}

Número 21(1), junio2016

revistes.uab.cat/periferia

\section{Reseña de "Memorias del caso peruano de esterilización forzada" de Alejandra Ballón, comp.}

\author{
Ainhoa Molina Serra ${ }^{1}$ \\ GRAFO - Departamento de antropología social y cultural, \\ UniversitatAutònoma de Barcelona
}

DOI: http://dx.doi.org/10.5565/rev/periferia.492

\begin{abstract}
Resumen
Esta es una reseña crítica sobre el libro "Memorias del caso peruano de esterilización forzada" (2014), en el que la artista e investigadora social Alejandra Ballón compila cuatro ensayos que abordan el caso de las esterilizaciones forzadas ocurridas en Perú durante el Programa Nacional de Salud Reproductiva y Planificación Familiar (1996-2000) del gobierno del ex presidente Alberto Fujimori, ofreciéndonos diferentes perspectivas sobre un tema que, hasta hoy genera debate y es controvertido en la esfera política pública peruana.
\end{abstract}

Palabras Claves: indígenas, esterilización forzada, planificación familiar, Perú

\begin{abstract}
This is a critical review of the book "Memoirs of the Peruvian case of forced sterilization" (2014), in which the artist and social researcher Alejandra Ballon compiles four essays that address the case of forced sterilizations occurred in Peru during the National Program Reproductive Health and Family Planning (1996-2000) under the government of President Alberto Fujimori, offering different perspectives on an issue that has been hotly debated so far in either the political and public Peruvian sphere.
\end{abstract}

Key Words: indigenous peoples, forced sterilizations, family planning, Peru 


\section{perifèria}

Número 21(1), junio2016

revistes.uab.cat/periferia

\section{Introducción}

El tema de las esterilizaciones forzadas en Perú tiene una historia de 19 años y, durante este tiempo, "Memorias del caso peruano de esterilización forzada" ha sido el único libro publicado que se ha dedicado enteramente a trabajar esta cuestión. Hasta ahora solamente contábamos con los informes elaborados por la Defensoría del Pueblo, el Congreso de la República y algunas organizaciones de derechos humanos que, tras sus investigaciones sobre el funcionamiento del Programa Nacional de Salud Reproductiva y Planificación Familiar (1996-2000), ofrecieron detalles sobre los hechos acontecidos, sacando a la luz las ilegalidades que el gobierno del ex presidente Alberto Fujimori había cometido en la implementación de su política de planificación familiar. Asimismo, algunas académicas y académicos sociales han escrito someramente sobre este tema en el transcurso de sus propios trabajos de investigación sobre las políticas de género, de salud y de población (Boesten 2010;Ewig 2010; Leinaweaver 2005) y sobre el papel de los medios de comunicación en el Perú (Lerner 2009). Sin embargo, no ha sido hasta la publicación de este libro, que se ha contado con un trabajo exhaustivo únicamente dedicado a abordar este tema, y éste es el mérito que, a mi parecer, se le debe reconocer a esta obra y a su compiladora, A. Ballón, quien, en su afán por divulgar y estimular un debate público sobre el caso de esterilizaciones en Perú, ha reunido a destacados profesionales e investigadores que, mediante sus ensayos, nos proporcionan diferentes perspectivas sobre un asunto que hasta la actualidad no había sido abordado por la comunidad académica.

\section{Contenido del libro}

Esta publicación tiene como fin último denunciar públicamente el delito de esterilizaciones forzadas en Perú. Así lo expresa Kimberly Theidon en la presentación cuando afirma que:

"La meta de este libro es ilustrar las consecuencias de estos crímenes de lesa humanidad infligidos a miles y miles de mujeres y hombres, con los 


\section{perifèria}

Número 21(1), junio2016

revistes.uab.cat/periferia

que la sociedad peruana tiene una deuda pendiente en consecuencia a lo que el Estado hizo en nombre del desarrollo y el progreso" (p. 16-17)

Así pues, en el primer artículo, la politóloga Christina Ewig se propone demostrar cómo la administración del ex presidente Fujimori promovió una política de población antinatalista de corte neomaltusiano. Ewig utiliza el concepto de «uso instrumental de la mujer» para definir el programa de planificación familiar en el Perú como una política cuyo objetivo final era reducir los niveles de pobreza y acelerar el crecimiento económico del país, siendo el cuerpo de la mujer un instrumento cuyas capacidades reproductivas debían ser controladas en aras de velar por el desarrollo económico por encima de los derechos humanos. Ewig contextualiza la política de población peruana dentro de las políticas demográficas mundiales promovidas por los llamados "países industrializados o desarrollados" y que tienen su origen en la teoría de Thomas Malthus (1798) que vincula directamente el control demográfico con el desarrollo económico y que derivó, a partir de 1883, en políticas eugenésicas globales.

A continuación, el Dr. Gonzalo Gianella, médico de profesión, nos ilustra con un ensayo crítico respecto a la posición que ha adoptado el cuerpo médico peruano en el tema de las esterilizaciones forzadas. Gianella argumenta que los médicos tuvieron un papel principal en la ejecución de la política de planificación familiar, puesto que éstos contaban con el poder de negarse a realizar las operaciones de esterilización y, por ello, critica la actitud de aquellos médicos que se han salvaguardado bajo la excusa de la precariedad laboral alegando que se vieron presionados por el gobierno para conseguir metas numéricas de pacientes esterilizadas a cambio de conservar sus puestos de trabajo. Bajo este pretexto, los médicos -dice Gianella- han evitado colocarse en la incómoda posición de perpetradores de un delito para pasar a ocupar, también, la posición de víctimas de un sistema perverso. Con estos argumentos, Gianella llama la atención al cuerpo médico peruano para que asuma su responsabilidad en la ejecución directa del programa de planificación familiar y pida perdón públicamente a las víctimas de dicha política. 


\section{perifèria}

Número 21(1), junio2016

revistes.uab.cat/periferia

Por su parte, GabriellaCitroni, jurista y con una larga trayectoria profesional en defensa de los derechos humanos, nos ofrece, en el tercer capítulo, un análisis del caso peruano de esterilizaciones forzadas a través de su enfoque jurídico tipificándolo como crimen de lesa humanidad, crimen de guerra o genocidio según las normas del derecho penal internacional y ubicándolo dentro de otros tipos penales según el derecho interno del estado peruano. Citroni enfatiza la necesidad de juzgar a los responsables de estos delitos y de garantizar a las víctimas el acceso a la justicia. Asimismo, la autora no pierde la oportunidad de reprocharle a la Comisión de la Verdad y Reconciliación su falta de voluntad para incluir la investigación de las esterilizaciones forzadas dentro de su mandato.

Finalmente, contamos con el cuarto y último capítulo de este libro escrito por Giulia Tamayo, quien ejerció como abogada y fue de las primeras personas en hacer públicos los abusos del programa de planificación familiar de Fujimori. Tamayo, ya fallecida, nos presenta un ensayo en el que, en sus propias palabras:

"Busca, por un lado, contribuir al esclarecimiento de los hechos y su reconocimiento como ilícitos en el derecho internacional a fin de que sean perseguidos judicialmente $y$ se satisfagan los derechos de las víctimas; $y$, de otro lado, alertar sobre las ideas que se recrean para obstaculizar la verdad, justicia y reparación" (p. 126)

Asimismo, Tamayo, nos recuerda que han pasado casi veinte años desde que salieron a la luz las primeras denuncias sobre esterilizaciones forzadas, sin que hasta la fecha se hayan depurado responsabilidades y critica la falta de voluntad política para avanzar en la obtención de justicia.

Y para terminar, estos cuatro ensayos vienen acompañados -a modo de anexosde los testimonios que la investigadora A. Ballón obtuvo durante su trabajo de campo en Piura, Ayacucho y Lima. A través de estos testimonios, Ballón pretende mostrar las consecuencias que las mujeres han sufrido tras la operación de ligadura de trompas, entre las que subraya que las mujeres de Huancabamba (Piura) han dejado de tejer con kallwa -su tradicional telar de cintura- debido al dolor que les 


\section{perifèria}

Número 21(1), junio2016

revistes.uab.cat/periferia

ocasiona amarrarse el telar a la cintura, trayendo como consecuencia la disminución de ingresos económicos y la pérdida de la transmisión generacional de madres a hijas- de los valores y costumbres locales. Asimismo, Ballón menciona que la mayoría de las mujeres a quienes ella ha entrevistado han sido abandonadas por sus esposos debido a que, tras la operación, las mujeres han perdido libido y ello perjudica la relación sexual con sus cónyuges, siendo además, estigmatizadas como mujeres fáciles e inútiles como consecuencia de haber perdido su función progenitora.

\section{Los límites del enfoque en derechos humanos y los riesgos de la victimización}

Este es un libro de denuncia. Delito, víctimas y justicia, probablemente son las palabras más reiteradas a lo largo del texto y que dejan en el lector -como mínimo- dos ideas muy claras: que el estado peruano ha cometido delitos de esterilización forzada y que existen víctimas que todavía esperan justicia.

Efectivamente, en el marco de la política de planificación familiar de Fujimori se cometieron muchos abusos y eso es incuestionable. $Y$ aunque eso no es algo nuevo que no se supiese ya por los informes de la Defensoría del Pueblo, las noticias de prensa y los debates políticos que suelen generarse contra el Fujimorismo durante las campañas electorales, lo que sí hace esta publicación es contribuir a denunciarlo desde las voces académicas de reconocidos profesionales y a mantenerlo presente y en la esfera pública. Sin embargo, hay algo sobre lo que me gustaría llamar la atención para que el tema de las esterilizaciones en Perú no quede circunscrito únicamente al ámbito de la denuncia. Se trata de advertir sobre el riesgo de la victimización como discurso único y de señalar que el contenido de la categoría "víctima" es más amplio, pudiendo incluso cuestionarse cómo se lleva a cabo la construcción de dicha identificación: quién la construye, bajo qué criterios lo hace y quién tiene la legitimidad para otorgar esa categoría a otros o cómo esos otros se apropian o no de esa identidad. 


\section{perifèria}

Número 21(1), junio2016

revistes.uab.cat/periferia

En mi opinión, si hay algo que se le puede criticar a este libro es, precisamente, que su enfoque se centra únicamente en los derechos humanos y enfatiza tanto la idea de victimización, que no nos ayuda a entender el tema de las esterilizaciones en toda su dimensión.Asimismo, pueden generar cierta inquietud algunas expresiones o palabras recogidas en los testimonios anexados al final del libro, más orientadas a un interrogatorio judicial que a una investigación antropológica. Considero que el tema de las esterilizaciones en Perúpresenta una dimensión que va más allá de identificar víctimas y exigir justicia -aun siendo ambos objetivos loables y necesarios-y, por ello, los investigadores en ciencias sociales deben esforzarse por comprender qué hay detrás de esas categorías.

Las condiciones económicas de las familias, las expectativas de progreso que las madres y padres albergan para sus hijos, la toma de decisiones respecto a la reproducción, los roles de género en la relación de pareja y en la organización del trabajo, las construcciones locales sobre el cuerpo, la sexualidad, el dolor y la enfermedad, son solo algunos de los muchos temas que se podrían trabajar cuando se investiga sobre el caso de las esterilizaciones -forzadas o no- en Perú y que complementarían esa experiencia enriqueciendo el debate académico para que podamos entender esa vivencia más allá de un evento aislado y alcancemos a dimensionarla entro de las historias de vida de estas mujeres y hombres esterilizados, contextualizándola y dándole sentido.

Esta reflexión tiene como propósito que se evite tropezar con la -a veces pequeña trampa- de la victimización que, en última instancia, termina por invisibilizar las historias de personas individuales y por reproducir, precisamente, las jerarquías contra las que se quiere luchar. A colación, me viene a la memoria una frase de M. Cristina Alcalde en una publicación reciente donde presenta un estudio sobre la violencia contra las mujeres en la ciudad de Lima y apunta que:

"los estudios sobre la violencia, por lo general, vuelven invisibles a las mujeres individuales al centrarse más bien en los actos o episodios de violencia como si estos pudiesen ser desconectados de las complicadas vidas de las mujeres individuales y de los mundos socioculturales en los que acontecen tales vidas" (Alcalde 2014: 15) 


\section{perifèria}

Número 21(1), junio2016

revistes.uab.cat/periferia

A mi parecer, éste es el riesgo que se puede correr al analizar el tema de las esterilizaciones en Perú centrándolo prácticamente de forma exclusiva en el enfoque de los derechos humanos, dificultándonos ver que también hay espacio para otros planteamientos posibles.

\section{Conclusiones}

Para finalizar, quiero insistir en que el mérito que debe reconocerse a este libro estriba en ser, hasta día de hoy, el único trabajo académico dedicado enteramente a abordar el tema de las esterilizaciones en Perú. Asimismo, cabe valorar el esfuerzo de quienes escriben en él por contribuir a la lucha por el reconocimiento de los derechos humanos de quienes han sufrido, contra su voluntad, las consecuencias de una política verdaderamente injusta. $Y$ especialmente, agradecerle a A. Ballón por su lucha personal y su afán por divulgar y estimular el debate público sobre un tema que, hasta ahora, ha pasado desapercibido a la comunidad académica.

Concuerdo con la compiladora y con los demás autores de este libro en que cuando se discute sobre la política de esterilizaciones forzadas en Perú se debe hablar de víctimas, y no solamente de víctimas directas de una política abusiva, sino también de víctimas de un sistema patriarcal, jerarquizado y discriminatorio social y económicamente, no sólo en el ámbito político general, sino en el marco más local de sus propias familias y comunidades. Sin embargo, como apunta J.C. Agüero citando a Elisabeth Jelin:

"mantener la centralidad de la víctima en el discurso de los derechos humanos genera que no importe lo que la persona hizo, sino solamente lo que se le hizo. Ello nos quita al actor y nos entrega a un personaje indefenso, donde lo que ponemos de relieve es que haya sido violentado en sus derechos y que haya sufrido. Por lo tanto, revalorar al actor es contribuir a recuperar a todos estos sujetos en su humanidad compleja" (Agüero 2015: 98) 


\section{perifèria}

Número 21(1), junio2016

revistes.uab.cat/periferia

Es por ello que, para evitar convertir a las personas esterilizadas en personajes pasivos indefensos y para contribuir a un debate más amplio, enriqueciéndolo con diferentes perspectivas, es útil desviar a la víctima del centro del discurso y situar el tema de las esterilizaciones como un asunto que abarca muchas otras dimensiones de las vidas de estas familias y que nos permite controvertir las relaciones de poder y las luchas por el reconocimiento en las relaciones de género que marcan tanto las relaciones de pareja como las relaciones de ciudadanía con el Estado-.

En cualquier caso, quiero acentuar - por si cabe alguna duda- que de ninguna manera cabe eximir de responsabilidad al gobierno de Fujimori por la implementación de su política de planificación familiar, pues concuerdo con $A$. Ballón y con los autores de estos ensayos en que su programa fue delictivo y, en muchos casos, vulneró los derechos fundamentales de muchas mujeres y hombres peruanos, siendo necesario el juzgamiento de esos delitos. No obstante -aún reconociendo la contribución tan valiosa que la antropología puede aportar a la obtención de esa justicia- ese es el trabajo que les corresponde principalmente a los juristas; mientras que los investigadores sociales tienen la responsabilidad, además, de recuperar a todos esos sujetos activos en su humanidad compleja.

\section{Bibliografía}

Agüero, José Carlos (2015). Los rendidos. Sobre el don de perdonar. Lima: Instituto de Estudios Peruanos.

Alcalde, María Cristina (2014). La mujer en la violencia. Pobreza, género y resistencia en el Perú. Lima: Instituto de Estudios Peruanos.

Ballón, Alejandra (2014) comp.Memorias del caso peruano de esterilización forzada. Lima: Biblioteca Nacional del Perú. 


\section{perifèria}

Número 21(1), junio2016

revistes.uab.cat/periferia

Boesten, Jelke (2010). Intersecting inequalities: Women and social policy in Peru, 1990-2000. Penn StatePress.

Ewig, Christina ([2010] 2012). Neoliberalismo de la segunda ola: género, raza y reforma del sector salud en el Perú. Lima: Instituto de EstudiosPeruanos.

Leinaweaver, Jessaca (2005). "Mass Sterilizations and Child Circulations in Peru".Anthropology News, 46(1), pp. 13-18.

Lerner, Adrián (2009). Las polémicas mediáticas en la campaña de esterilizaciones masivas en el Perú de Fujimori (1994-1998) (Doctoral dissertation, Tesis inédita de Licenciatura). Pontificia Universidad Católica del Perú, Lima-Perú). 